\title{
Repeated decrease of CD4+ T-cell counts in patients with rheumatoid arthritis over multiple cycles of rituximab treatment
}

\author{
Matthieu Lavielle ${ }^{1,2,3 \dagger}$, Denis Mulleman ${ }^{1,24^{*}+}$, Philippe Goupille ${ }^{1,2}$, Clément Bahuaud ${ }^{1,2}$, Hsueh Cheng Sung ${ }^{1}$,
} Hervé Watier ${ }^{1,3}$ and Gilles Thibault ${ }^{1,3}$

\begin{abstract}
Background: Significant peripheral blood CD4+ T-cell depletion has been observed after a first cycle of rituximab, a monoclonal antibody directed against the CD20 antigen, which is currently used in rheumatoid arthritis. Of note, an absence of CD4+ T-cell decrease has been observed in non-responders. Herein, we describe CD4+ T-cell changes over repeated cycles of rituximab and their relationship with clinical outcomes.

Methods: Patients with rheumatoid arthritis who started rituximab between July 2007 and July 2013 were analyzed up to November 2014. Lymphocyte phenotyping and clinical assessments were performed before, and 3 and 6 months after each cycle. Lymphocytes counts and disease activity were compared at each time point, using nonparametric tests.

Results: Patients received up to seven cycles of treatment during the study period. Mean CD4+ T-cell counts were above the upper limit of the reference range before each rituximab infusion and repeatedly reached the reference range at 6 months (and/or 3 months) post infusion. CD4+ T cells decreased concurrently with disease activity score.

Conclusions: CD4+ T-cell counts could be a relevant biomarker of response to rituximab in rheumatoid arthritis and could be considered in making decisions about the timing of retreatment.
\end{abstract}

Keywords: Rheumatoid arthritis, Rituximab, CD4+ T cells, Biomarker

\section{Background}

Targeting B cells with rituximab (RTX), a chimeric monoclonal antibody directed against the CD20 antigen, induces a sustained clinical improvement in most patients with rheumatoid arthritis (RA) [1, 2]. Patients who respond to treatment are likely to receive multiple repeated cycles of RTX upon relapse.

RTX leads to depletion of both normal and autoreactive B cells and this effect is almost complete in blood and partial in bone marrow [3-7]. The latter population is responsible for the production of rheumatoid factor (RF) and anti-citrullinated protein antibodies (ACPAs), both hallmarks of RA. Although some studies have

\footnotetext{
* Correspondence: denis.mulleman@univ-tours.fr

${ }^{\dagger}$ Equal contributors

${ }^{1}$ Université François-Rabelais de Tours, CNRS, UMR 7292, Tours, France

${ }^{2}$ Service de Rhumatologie, CHRU de Tours, Tours, France

Full list of author information is available at the end of the article
}

shown that RF $[8,9]$ or ACPA [8] positivity are associated with clinical response, RTX is also effective in the RF-negative and ACPA-negative forms of RA. Additionally, Cambridge et al. observed a post-RTX decrease in RF and ACPA but neither the pre-treatment levels nor the changes observed after treatment were predictive of response to treatment [10]. These data suggest that the efficacy of RTX in RA may depend on B-cell functions unrelated to autoantibody production.

We and others previously reported significant depletion of $\mathrm{CD} 4+\mathrm{T}$ cells in peripheral blood in patients receiving a first cycle of RTX for treatment of RA [11, 12]. Interestingly, patients who were non-responders to this first cycle tended to experience a milder depletion of $\mathrm{CD} 4+\mathrm{T}$ cells than responders, whereas depletion of $\mathrm{B}$ cells was similar in both groups. However, the relationship between changes in CD4+ T cells and clinical outcomes over repeated cycles of RTX has not been studied. The 
aim of the present study was to describe and characterize the changes in CD4+ T cells over multiple, repeated cycles of RTX and to investigate the potential relationship between these changes and disease activity.

\section{Methods}

\section{Patients and study protocol}

Patients seen in routine clinical practice, who started RTX for the treatment of RA between July 2007 and July 2013, were included in this retrospective study. The present study is based on data collected during follow up to November 2014. Therefore, some patients included at the end were not followed up for as long as those who were recruited at the beginning. Patients received two infusions of $1000 \mathrm{mg}$ of RTX as previously described. Clinical improvement (measured by the Disease Activity Score in 28 joints using erythrocyte sedimentation rate (DAS 28-ESR) and clinical tolerance were assessed 3 months (M3) and 6 months (M6) post infusion [11]. Radiographs were available at baseline, but radiographic progression was not assessed systematically. Percycle clinical response using European League Against Rheumatism (EULAR) criteria was calculated for each patient relative to the baseline DAS 28-ESR of the first cycle [13]. Decisions about retreatment and treatment intervals were based on clinical response to the previous cycle and symptoms of relapse after M6 (as-needed basis). Lymphocyte phenotyping was carried out before each infusion and at follow-up visits as per routine procedure, without additional sampling.

\section{Lymphocyte phenotyping by flow cytometry}

Lymphocyte phenotyping was performed as previously described according to a standard no-wash, whole-blood procedure using a PrepPlus and a TQ-Prep workstation or a FP1000 workstation (Beckman Coulter) and an Epics XL-MCL or a Navios flow cytometer (Beckman Coulter) [11].

\section{Statistical analysis}

Statistical analysis was performed using GraphPad Prism $^{\circ}$ software (version 6.0 for Macintosh; GraphPad Software, San Diego, CA, USA). Wilcoxon's matchedpairs signed rank test was used for analysis of paired data and differences in continuous variables between non-paired data were assessed using the Mann-Whitney nonparametric test. Results are presented as median and range (minimum $(\min )$-maximum $(\max )$ ) or interquartile range (IQR) for continuous variables. Kaplan-Meier curves were used to study the persistence of patients under rituximab. The significance level was set at $5 \%$ $(p<0.05)$.

\section{Results}

Mean global disease activity, CD19+ B-cell and CD4+ T-cell counts over multiple cycles of RTX

Fifty-four patients started RTX during the study period. Patients' characteristics are presented in Table 1. The time interval between each cycle is presented in Fig. 1. Maintenance to treatment is presented in Fig. 2. Median time to RTX discontinuation was 42 months. Adverse events were responsible for discontinuation in 4 of the 54 patients after the first cycle. Changes in disease activity and lymphocyte counts over repeated cycles of RTX are presented in Fig. 3. For each cycle, values are presented at three time points, i.e. before the first infusion, before the second infusions two weeks apart and at 3 or 6 months thereafter. All but one patient received methylprednisolone.

Repeated RTX treatment led to sustained clinical improvement with the mean post-treatment DAS28-ESR tending to decrease with the number of cycles (Fig. 3a). Clinical improvement was delayed with B-cell depletion, the latter being achieved before the second infusion in most patients (Fig. $3 \mathrm{~b}$ ). Whilst the cycle 1 pre-treatment B-cell count was within the normal reference range, it remained substantially below the lower limit of the reference range $\left(<200 / \mathrm{mm}^{3}\right)$ thereafter, and tended to decrease with the number of cycles. Hence, patients

Table 1 Baseline characteristics of the 54 patients

\begin{tabular}{ll}
\hline Characteristics & Baseline value \\
\hline Age, years & $60(36-84)$ \\
Sex, $n$ (\%) female & $42(78)$ \\
Disease status & \\
Disease duration, years & $16(1-36)$ \\
Disease Activity Score in 28 joints-erythrocyte & $5.3(2.1-7.7)$ \\
sedimentation rate & $33.4(3.0-111.0)$ \\
Erythrocyte sedimentation rate, mm/h & $17(1-166)$ \\
C-reactive protein, mg/L & $38(70)$ \\
Rheumatoid factor positivity, $n$ (\%) & $47(87)$ \\
Anti-cyclic citrullinated peptide positivity, $n(\%)$ & $42(78)$ \\
Radiologic evidence of erosions, $n$ (\%) & \\
Previous treatment, $n$ (\%) & $42(78)$ \\
Anti-tumor necrosis factor-a & $24(52)$ \\
Methotrexate & $42(78)$ \\
Prednisone & \\
Lymphocyte immunophenotype & $211(25-706)$ \\
CD19+ cells/mm3 & $1,740(323-3,378)$ \\
CD3+ cells/mm3 & $1,192(233-2,882)$ \\
CD4+ cells/mm3 & $482(120-1,114)$ \\
CD8+ cells/mm3 &
\end{tabular}

Values are the median (min-max) unless stated otherwise 


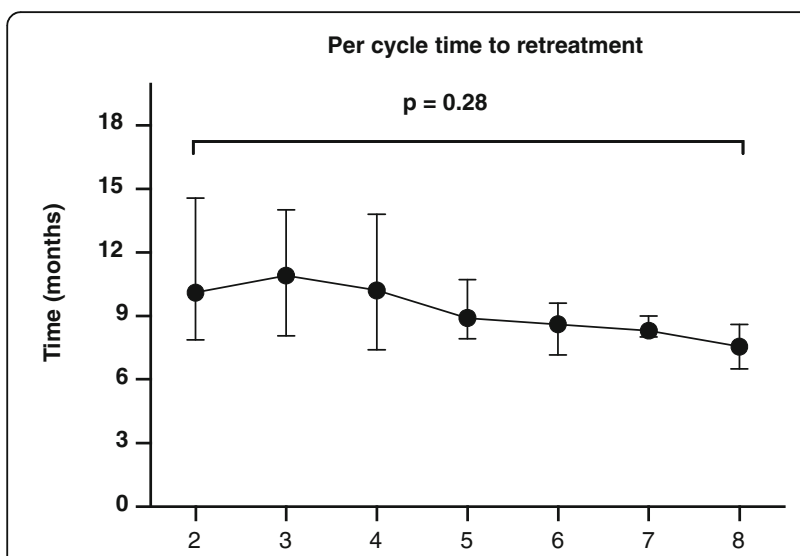

Fig. 1 Time interval between each rituximab cycle. Results are presented as median and interquartile range

were usually retreated before recovery of the circulating B-cell pool.

The changes occurring in CD4+ T-cell counts were somewhat different (Fig. 3c). First, mean CD4+ T-cell counts before RTX infusions were systematically above the upper limit of the reference range $\left(>1100 / \mathrm{mm}^{3}\right)$. They were higher in women than in men $(p<0.01)$, in patients without RF than in those with RF $(p<0.04)$, in patients without radiologic evidence of erosion than in those with evidence of erosion $(p<0.03)$ and in RTX first-cycle responders than in non-responders $(p<0.03)$. Of note, there was a trend towards higher pre-treatment $\mathrm{CD}^{+}{ }^{+} \mathrm{T}$-cell counts in patients previously treated with TNF inhibitors as compared to patients not previously treated $(p<0.09)$. Second, the mean post-treatment counts (M3 or M6) were substantially decreased (within the reference range), regardless of the cycle. The decreased CD4+ T-cell counts were independent of sex, RF and ACPA status, erosion status and co-medication with corticosteroids or methotrexate (data not shown).

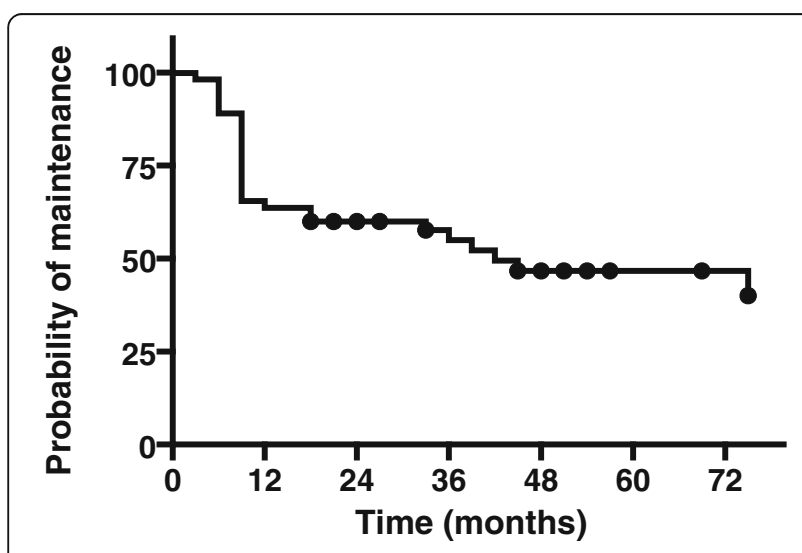

Fig. 2 Probability of rituximab maintenance versus time in 54 patients with rheumatoid arthritis

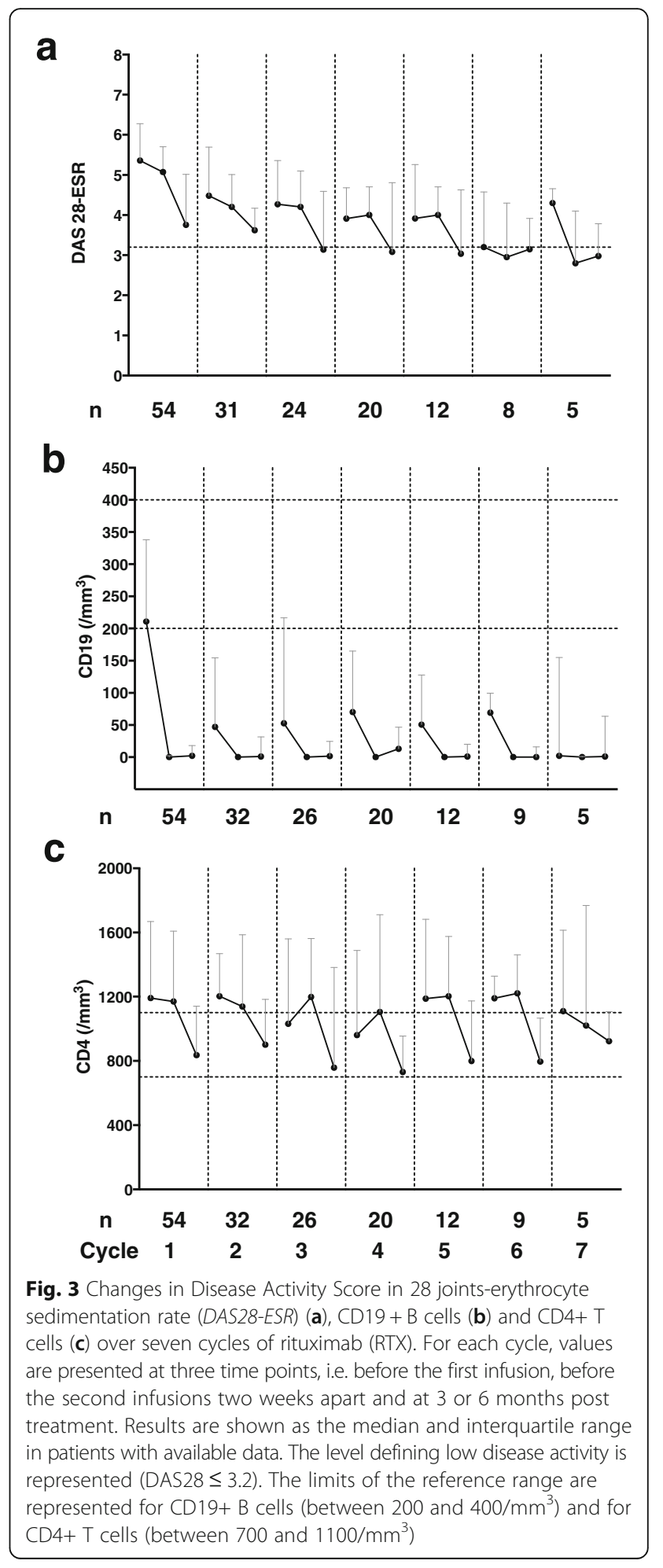

The decrease was delayed compared to B-cell depletion and was closely related to clinical improvement. Of note, there was no correlation between the CD4+ T-cell count and DAS28 at baseline (data not shown). Finally, CD4+ T-cell recovery was almost complete at the time of each 
Table 2 DAS28, CD 19+ cell count, CD4+ cell count at baseline, post treatment (M3/M6) and at the time of retreatment during the first cycle in 32 patients who received a second cycle of rituximab

\begin{tabular}{|c|c|c|c|c|c|c|c|c|c|}
\hline & \multicolumn{3}{|l|}{ DAS28-ESR } & \multicolumn{3}{|c|}{ CD19+ (cells/mm³) } & \multicolumn{3}{|l|}{ CD4+ (cells $/ \mathrm{mm}^{3}$ ) } \\
\hline & Pre-treatment & Post treatment & Retreatment & Pre-treatment & Post treatment & Retreatment & Pre-treatment & Post treatment & Retreatment \\
\hline Men $(n=7)$ & $5.4(4.1-6.0)$ & $4.4(2.0-5.1)$ & $3.8(3.2-5.3)$ & $180(45-237)$ & $9(0-87)^{*}$ & $50(3-138)^{*}$ & $962(703-1047)$ & 652 (393-853) & $1146(702-1412)$ \\
\hline Women $(n=25)$ & $5.2(4.6-6.2)$ & $3.3(2.7-4.7)^{* *}$ & $4.6(3.8-5.9)^{* *}$ & $320(179-411)$ & $3(0-36)^{* *}$ & $44(11-171)^{* *}$ & $1329(1015-1873)$ & $988(772-1498)^{* *}$ & $1325(964-1549)^{*}$ \\
\hline$R F+(n=22)$ & $5.3(4.3-6.1)$ & $3.6(2.6-5.1)^{* *}$ & $4.3(3.5-5.5)$ & $271(124-387)$ & $3(0-21)^{* *}$ & $47(10-134)^{* *}$ & $1041(908-1640)$ & $875(603-1305)^{*}$ & $1033(826-1513)$ \\
\hline$R F-(n=10)$ & $5.2(4.7-6.3)$ & $3.3(3.1-4.6)^{*}$ & $4.6(3.6-5.8)^{*}$ & $275(191-386)$ & $15(0-55)^{* *}$ & $45(8-263)^{*}$ & $1442(1121-2048)$ & $1044(864-1386)^{* *}$ & $1376(1212-1637)^{*}$ \\
\hline Erosion $(n=24)$ & $5.8(4.3-6.4)$ & $3.7(2.6-5.1)^{* *}$ & $4.6(3.5-5.8)^{*}$ & $233(143-325)$ & $3(0-40)^{* *}$ & $47(7-131)^{* *}$ & 1119 (953-1708) & $998(639-1514)^{* *}$ & $1328(927-1584)^{*}$ \\
\hline No erosion $(n=8)$ & $5.0(4.7-5.3)$ & $3.4(2.7-4.3)^{*}$ & $4.2(3.5-5.4)$ & $371(147-541)$ & $4(1-38)$ & $100(22-229)^{*}$ & $1289(912-2201)$ & $939(869-981)^{*}$ & $1112(958-1345)^{*}$ \\
\hline TNFi $(n=27)$ & $5.2(4.5-6.3)$ & $3.6(2.7-5.0)^{* *}$ & $4.3(3.4-5.8)^{*}$ & $237(141-332)$ & $3(0-30)^{* *}$ & $44(9-138)^{* *}$ & $1248(995-1732)$ & $988(652-1464)^{* *}$ & $1331(1029-1620)^{*}$ \\
\hline No TNFi $(n=5)$ & $5.8(4.4-6.0)$ & $2.8(2.4-5.0)$ & $4.4(3.9-5.0)$ & $433(244-523)$ & $3(1-256)$ & $68(8-360)$ & 819 (739-1733) & 691 (323-907) & 918 (727-981) \\
\hline
\end{tabular}

Patients were grouped according to the following subgroups: men/women, rheumatoid factor (RF)+/RF-, erosion/no-erosion, previous TNF inhibitor (TNFi)/no previous TNFi. Results are presented as median and interquartile range. DAS28-ESR Disease Activity Score in 28 joints-erythrocyte sedimentation rate. Wilcoxon's matched-pairs signed rank test was used to compare values post treatment vs pre-treatment, and retreatment vs post treatment: ${ }^{*} p<0.05,{ }^{* *} p<0.005$ 
re-treatment. Changes in DAS 28, CD19+ and CD4+ cells, according to categories of patients (i.e. men vs women, RF+ vs RF-, erosion vs non-erosion, previous TNF inhibitors vs no previous TNF inhibitors) during the first cycle are presented in Table 2 for the 32 patients who received a second cycle.

\section{Per-cycle variation in CD4+ T-cell counts induced by RTX}

To more precisely describe the dynamic changes induced by RTX, CD4+ cell counts were compared at three time points in each cycle: pre-treatment, post treatment (i.e. at
M6 or at M3 if M6 data were unavailable) and retreatment (i.e. before the first infusion of the next cycle). For these per-cycle analyses, only retreated patients were included (Fig. 4) in order to describe both decrease and recovery phases. For all cycles except cycle 3 and cycle 6, mean post-treatment CD4+ values were significantly lower than mean pre-treatment or retreatment values. The mean posttreatment count tended to decrease slightly upon repeated cycles, reaching the lower limit of the reference range after cycle 4. Furthermore, RTX led to dramatically decreased post-treatment $\mathrm{CD} 4+$ cell counts, i.e. $\leq 300$ cells $/ \mathrm{mm}^{3}$
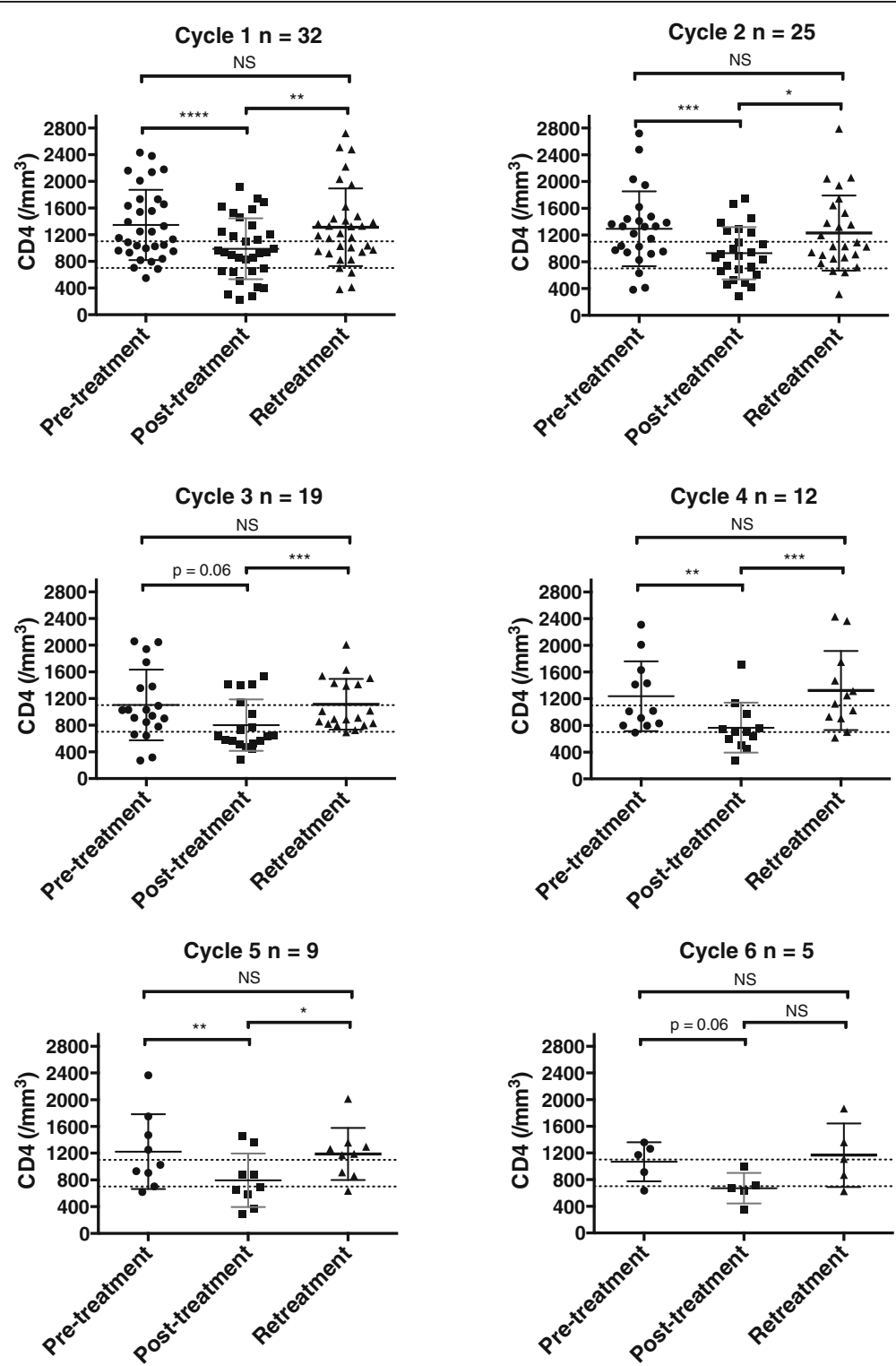

Fig. 4 Per-cycle analysis of pre-treatment, post-treatment and retreatment counts of CD4+ T cells. In each cycle only patients for whom data were available were included. Each dot represents one patient and lines represent the mean with SD. The limits of the reference range are presented (between 700 and $1100 / \mathrm{mm}^{3}$ ). CD4+ cell counts were compared between the three points, i.e. before treatment, 3 or 6 months post treatment and before retreatment for each cycle usingWilcoxon's matched-pairs signed rank test: ${ }^{* * *} p<0.0001,{ }^{* * *} p<0.001,{ }^{* *} p<0.005,{ }^{*} p<0.05$; NS not significant 
in 8/54 patients (6 patients in the first cycle), including in one patient who presented with extensive oropharyngeal candidiasis. This effect was independent of the number of cycles and of the previous cycle variation in CD4+ T-cell counts. Finally, mean pre-treatment and retreatment values were not significantly different. The changes in CD4+ T-cell counts in the eight patients with a value of $<300 / \mathrm{mm}^{3}$ at least once during follow up are presented in Fig. 5. The relationship between adverse events and lymphocyte phenotyping will be studied in a separate report, and therefore will not be presented in the present article.

\section{Clinical response and CD4+ T-cell changes observed during cycle 2, in cycle 1 non-responders}

We then focused on 10 patients who were retreated despite a poor response in cycle 1. The DAS28-ESR and CD4+ T-cell changes in these patients are shown in Fig. 6a and $\mathrm{c}$ and those in initial responders in Fig. 6b and $\mathrm{d}$. Of the 10 responders, 8 initial non-responders became responders after the second cycle. The cycle- 2 post-treatment DAS28-ESR was decreased in these patients compared to cycle 2 pre-treatment and to cycle 1 pre-treatment and post treatment. In initial responders, the post-treatment DAS28-ESR was similar in cycles 1 and 2 and CD4+ T-cell counts were significantly and similarly decreased in both cycles. Conversely, in initial non-responders, CD4+ T-cell counts remained the same in cycle 1 ; however, in cycle 2 the post-treatment CD4+ T-cell counts tended to be lower than the pre-treatment values in both cycle 1 and cycle $2(p=0.08$ and $p=0.10$, respectively). Moreover, they were significantly decreased compared to cycle-1 post-treatment values, further suggesting a potential relationship between disease activity and CD4+ T-cell counts in patients with RA receiving RTX.

\section{Discussion}

Repeated cycles of RTX are known to induce sustained and sometimes improved efficacy in patients with RA [14]. We show here that improved clinical response observed in patients who received RTX on an as-needed
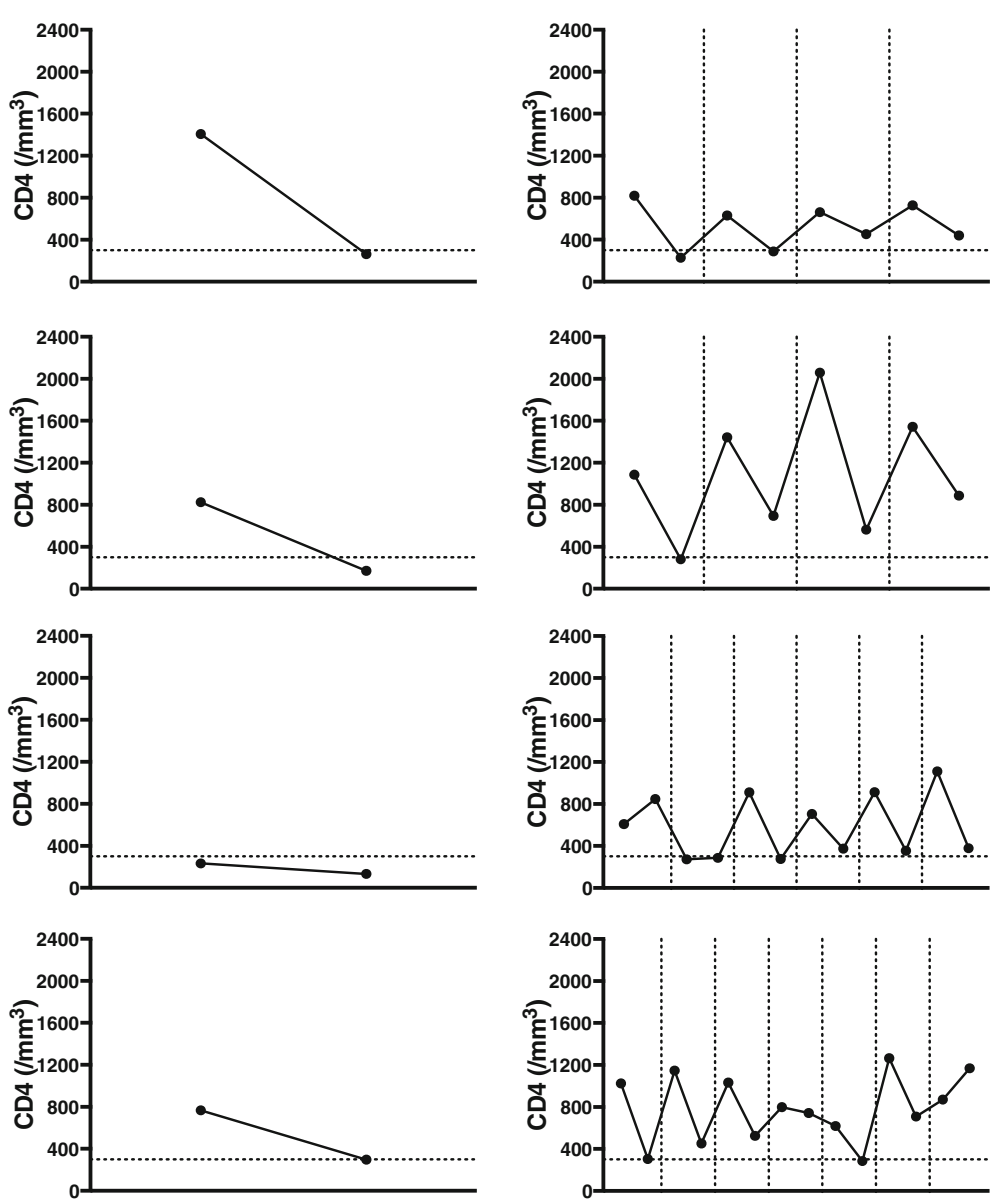

Fig. 5 Changes in CD4+ T cell counts in patients $(n=8 / 54)$ who experienced at least one decrease in the CD4+ cell count to below 300/mm3 during follow up 

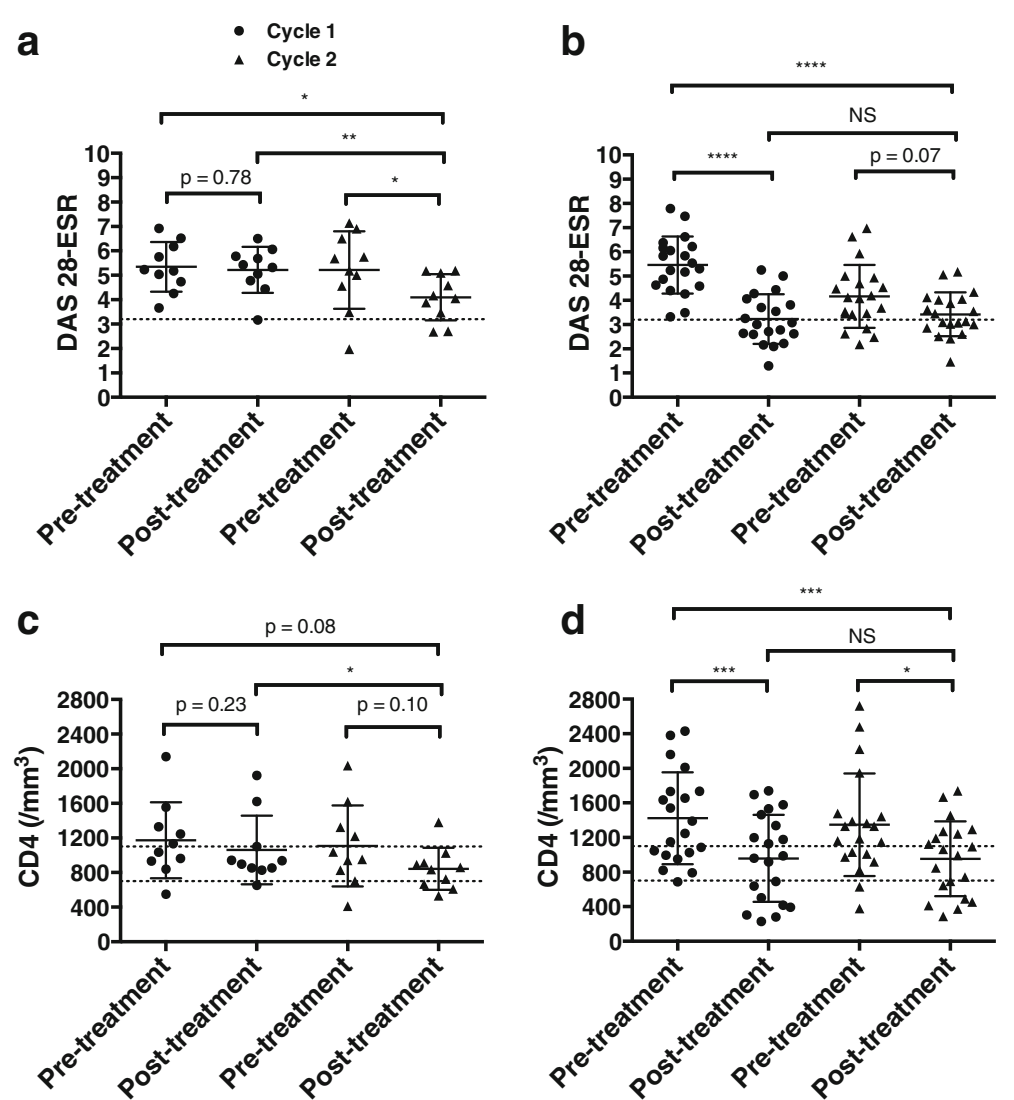

Fig. 6 Changes in Disease Activity Score in 28 joints-erythrocyte sedimentation rate (DAS28-ESR) (a, b) and CD4+ T-cell counts (c, d) over cycle 1 and cycle 2 in first-cycle non-responders $(\mathbf{a}, \mathbf{c})(n=10)$ and in first-cycle responders $(\mathbf{b}, \mathbf{d})(n=20)$. Pre-treatment and 3 or 6 months post-treatment data are shown as scatter dot plots (first cycle non-responders $n=10$; first-cycle responders, $n=20$ ). Each dot represents one patient and lines represent the mean with SD. For DAS28-ESR analysis, the level defining low disease activity is represented (DAS28 $\leq 3.2)$. Comparison of pre-treatment and post-treatment values was made using Wilcoxon's matched-pairs signed rank test: ${ }^{* * *} p<0.0001,{ }^{* * *} p<0.001,{ }^{* *} p<0.005,{ }^{*} p<0.05$; NS not significant

basis, was associated with repeated variation in CD4+ Tcell counts occurring over successive cycles.

The first finding of this study was that the mean CD4+ T-cell counts were above the upper limit of the reference range at baseline and before each RTX cycle. This result indicates that the homeostasis of CD4+ T cells was disrupted before RTX treatment and when the patients stopped responding. Interestingly, baseline CD4+ T-cell counts were significantly higher in responders than in non-responders on the one hand, and in patients without RF and in those without radiologic evidence of erosion on the other hand. These results might suggest that patients with less severe forms of the disease are more likely to respond to RTX. However, until now only the presence of RF $[8,9]$ or ACPA [8] has been identified as predictor of clinical response. Larger studies are required to confirm this conclusion and, eventually, to define a predictive threshold of CD4+ T-cell counts value for clinical response.

We have previously reported a substantial decrease in CD4+ T-cell counts in a large majority of patients with
RA receiving a first cycle of RTX. A decrease in CD4+ T cells was not observed in the absence of response following the first cycle [11]. The present study shows that a decrease in CD4+ T-cell counts occurred repeatedly along with clinical response in patients who received up to seven cycles of RTX. A slightly additive effect of repeated treatment was seen, with the mean posttreatment $\mathrm{CD} 4+\mathrm{T}$-cell count gradually reaching the lower limit of the normal range. Additionally, we found that a second cycle of RTX in initial non-responders led to a clinical response in 8 of 10 patients. The improvement in clinical response following this second cycle was associated with a decrease in CD4+ T-cell counts, which was not observed in the first cycle.

It is known that post-RTX B-cell recovery is a long process [3-7, 15]. Therefore, patients are usually retreated before complete recovery of the B-cell pool. There was a tendency toward a decrease in pretreatment CD19+ B-cell counts with repeated cycles. This may be due to a biologic effect of RTX, but it may also be explained by the gradual reduction in the time 
interval between each cycle that we observed. By contrast, an RTX-induced CD4+ T-cell decrease was followed by complete recovery of the circulating CD4+ T-cell pool at the end of each cycle. The time to CD4+ $\mathrm{T}$ cell recovery may vary across patients and may relate to the time to relapse. Also we previously reported that there was a greater decrease in the CD4+ T-cell count in patients whose time to retreatment was $>12$ months than in those whose time to retreatment was $<12$ months [11]. The assumption that CD4 could be a valuable marker is based on the coincidence between the clinician's decision whether to retreat and the CD4 recovery. It is indeed very apparent that recovery of $\mathrm{CD} 4+$ cells occurs at the time of the relapse. Taken together, these results show that in patients with RA receiving RTX, disease activity is more closely related to $\mathrm{CD} 4+\mathrm{T}$-cell variations than to $\mathrm{B}$-cell variations, suggesting that monitoring CD4+ T cells might be more relevant for predicting disease relapse. The present results reopen the issue of re-treatment timing, and suggest that a scheme of RTX administration based on CD4+ T-cell counts might anticipate and eventually avoid disease relapse.

\section{Conclusions}

Repeated post-treatment decrease in CD4+ T-cell counts over successive cycles of RTX occurs in patients with RA. Changes in CD4+ T-cell counts could be a relevant biomarker of RA activity in RTX-treated patients and hence aid the determination of an appropriate treatment schedule. The accuracy of CD4+ T-cell counts as a biomarker of disease activity and/or RTX efficacy needs to be confirmed by further prospective studies.

\section{Abbreviations}

ACPAs: Anti-citrullinated protein antibodies; DAS28: Disease Activity Score in 28 joints; ESR: Erythrocyte sedimentation rate; EULAR: European League Against Rheumatism; RA: Rheumatoid arthritis; RF: Rheumatoid factor; RTX: Rituximab

\section{Acknowledgements \\ The authors thank Drs Saloua Mammou, Isabelle Griffoul, Emilie Ducourau, Virginie Martaillé and Julien Mélet for clinical assessment. We are indebted to our nurses Nelly Jaccaz-Vallée, Sergine Gosset, Fabienne Chalier, Valérie Angebeau, Laetitia Cornec, Adeline Coutellier, Corinne Depont, Vanessa Fougeray, Valérie Fuseau, Pascale Guibout, Sophie Joncheray, Céline Letot, Isabelle Romier and Elodie Vigneron for blood sampling and commitment in taking care of patients, to Claude Gautier and Elisabeth Billant for performing blood sample staining and flow cytometry analysis and to Alexandra Farrell for linguistic revision and editing. Alexandra Farrell was supported by the program ("Investissements d'avenir Grant Agreement LabEx MAblmprove: ANR-10-LABX-53"). CNRS UMR 7292 participates in the Consortium «Monitoring of monoclonal Antibodies Group in Europe» (MAGE) for inflammatory diseases. The MAGE Consortium is supported by LE STUDIUM Loire Valley Institute for Advanced Studies (http://www.lestudium-ias.com/fr).}

\section{Funding}

This project was not supported by any specific grants from commercial companies and there were no conflicts of interest with commercial companies in either the preparation of, or support for this research.

\section{Authors' contributions}

ML participated in the clinical assessment, data collection, statistical analysis and interpretation of results and drafted the manuscript. DM contributed substantially to the study conception and design, participated in the clinical assessment and in the analysis and interpretation of results and drafted the manuscript. PG participated in clinical assessment, analysis and interpretation of results and revised the manuscript. CB and HSC participated in the analysis of results and revised the manuscript. HW participated in the analysis and interpretation of results and revised the manuscript. GT supervised the study conception and design and the flow cytometry analysis and drafted the manuscript. All authors read and approved the final manuscript.

\section{Authors' information}

Not applicable.

\section{Competing interests}

DM participated on behalf of his institution in clinical trials sponsored by Abbott, Roche, BMS, Pfizer, UCB and MSD; his hospital received a grant for research from Abbott in 2004 and from Nordic Pharma in 2012; he has acted as a consultant and given lectures on behalf of his institution for MSD, Pfizer, UCB and Novartis; he has been invited to attend international congresses by MSD, Roche, BMS, Abbott and Janssen-Cilag. PG participated on behalf of his institution in clinical trials sponsored by Abbott, Roche, BMS, Lilly, Novartis, Pfizer, UCB and MSD; he has acted as a consultant and given lectures for Abbott, BMS, MSD, Pfizer, UCB; he has been invited to attend international congresses by MSD, Roche, BMS and Abbott. ML, CB, HCS, HW and GT declared no conflicts of interest.

\section{Consent for publication}

All authors have approved the final manuscript and given their consent for publication of the manuscript.

\section{Ethics approval and consent to participate}

The treatment protocol, blood sampling and follow-up visits were performed as per routine procedure. Ethics approval and written consent were therefore not required for the data analyses.

\section{Author details}

${ }^{1}$ Université François-Rabelais de Tours, CNRS, UMR 7292, Tours, France. ${ }^{2}$ Service de Rhumatologie, CHRU de Tours, Tours, France. ${ }^{3}$ Laboratoire d'Immunologie, CHRU de Tours, Tours, France. ${ }^{4}$ GICC - UMR 7292, UFR de Médecine, Bâtiment Vialle, 10 boulevard Tonnellé, BP 3223, 37032 Tours, Cedex 01, France.

Received: 22 April 2016 Accepted: 10 October 2016

Published online: 28 October 2016

\section{References}

1. Cohen SB, Emery P, Greenwald MW, Dougados M, Furie RA, Genovese MC, Keystone EC, Loveless JE, Burmester GR, Cravets MW, et al. Rituximab for rheumatoid arthritis refractory to anti-tumor necrosis factor therapy: Results of a multicenter, randomized, double-blind, placebo-controlled, phase III trial evaluating primary efficacy and safety at twenty-four weeks. Arthritis Rheum. 2006;54(9):2793-806.

2. Edwards JC, Szczepanski L, Szechinski J, Filipowicz-Sosnowska A, Emery P, Close DR, Stevens RM, Shaw T. Efficacy of B-cell-targeted therapy with rituximab in patients with rheumatoid arthritis. N Engl J Med. 2004;350(25):2572-81.

3. Dass S, Rawstron AC, Vital EM, Henshaw K, McGonagle D, Emery P. Highly sensitive $B$ cell analysis predicts response to rituximab therapy in rheumatoid arthritis. Arthritis Rheum. 2008;58(10):2993-9.

4. Leandro MJ, Cambridge G, Ehrenstein MR, Edwards JC. Reconstitution of peripheral blood $B$ cells after depletion with rituximab in patients with rheumatoid arthritis. Arthritis Rheum. 2006;54(2):613-20.

5. Nakou M, Katsikas G, Sidiropoulos P, Bertsias G, Papadimitraki E, Raptopoulou A, Koutala H, Papadaki HA, Kritikos H, Boumpas DT. Rituximab therapy reduces activated $B$ cells in both the peripheral blood and bone marrow of patients with rheumatoid arthritis: depletion of memory B cells correlates with clinical response. Arthritis Res Ther. 2009;11(4):R131.

6. Rehnberg M, Amu S, Tarkowski A, Bokarewa MI, Brisslert M. Short- and long-term effects of anti-CD20 treatment on B cell ontogeny in bone 
marrow of patients with rheumatoid arthritis. Arthritis Res Ther. 2009;11(4):R123.

7. Roll P, Palanichamy A, Kneitz C, Dorner T, Tony HP. Regeneration of B cell subsets after transient $B$ cell depletion using anti-CD20 antibodies in rheumatoid arthritis. Arthritis Rheum. 2006;54(8):2377-86.

8. Sellam J, Hendel-Chavez H, Rouanet S, Abbed K, Combe B, Le Loet X, Tebib J, Sibilia J, Taoufik Y, Dougados M, et al. B cell activation biomarkers as predictive factors for the response to rituximab in rheumatoid arthritis: a six-month, national, multicenter, open-label study. Arthritis Rheum. 2011;63(4):933-8.

9. Quartuccio L, Fabris M, Salvin S, Atzeni F, Saracco M, Benucci M, Cimmino M, Morassi P, Masolini P, Pellerito R, et al. Rheumatoid factor positivity rather than anti-CCP positivity, a lower disability and a lower number of anti-TNF agents failed are associated with response to rituximab in rheumatoid arthritis. Rheumatology (Oxford). 2009;48(12):1557-9.

10. Cambridge G, Leandro MJ, Edwards JC, Ehrenstein MR, Salden M, Bodman-Smith M, Webster AD. Serologic changes following B lymphocyte depletion therapy for rheumatoid arthritis. Arthritis Rheum. 2003;48(8):2146-54.

11. Mélet J, Mulleman D, Goupille P, Ribourtout B, Watier H, Thibault G. Rituximab-induced $T$ cell depletion in patients with rheumatoid arthritis: association with clinical response. Arthritis Rheum. 2013;65(11):2783-90.

12. Piantoni S, Scarsi M, Tincani A, Airo P. Circulating CD4+ T-cell number decreases in rheumatoid patients with clinical response to rituximab. Rheumatol Int. 2015;35(9):1571-3.

13. van Gestel $A M$, Prevoo ML, van 't Hof MA, van Rijswijk $M H$, van de Putte $L B$, van Riel PL. Development and validation of the European League Against Rheumatism response criteria for rheumatoid arthritis. Comparison with the preliminary American College of Rheumatology and the World Health Organization/International League Against Rheumatism Criteria. Arthritis Rheum. 1996;39(1):34-40.

14. Keystone EC, Cohen SB, Emery P, Kremer JM, Dougados M, Loveless JE, Chung C, Wong P, Lehane PB, Tyrrell H. Multiple courses of rituximab produce sustained clinical and radiographic efficacy and safety in patients with rheumatoid arthritis and an inadequate response to 1 or more tumo necrosis factor inhibitors: 5-year data from the REFLEX study. J Rheumatol. 2012;39(12):2238-46.

15. Roll P, Dorner T, Tony HP. Anti-CD20 therapy in patients with rheumatoid arthritis: predictors of response and $B$ cell subset regeneration after repeated treatment. Arthritis Rheum. 2008;58(6):1566-75.

\section{Submit your next manuscript to BioMed Central and we will help you at every step:}

- We accept pre-submission inquiries

- Our selector tool helps you to find the most relevant journal

- We provide round the clock customer support

- Convenient online submission

- Thorough peer review

- Inclusion in PubMed and all major indexing services

- Maximum visibility for your research

Submit your manuscript at www.biomedcentral.com/submit

Biomed Central 